\title{
necropolítica, governo sobre as infâncias negras e educação do rosto
}

\author{
divino josé da silva ${ }^{1}$ \\ universidade estadual paulista, presidente prudente, são paulo, brasil \\ orcid id: https:/ / orcid.org/0000-0003-0000-1268 \\ jonas rangel de almeida ${ }^{2}$ \\ universidade estadual paulista, marília, são paulo, brasil \\ orcid id: https:/ / orcid.org/0000-0001-7505-4896 \\ pedro angelo pagni ${ }^{3}$ \\ universidade estadual paulista, marília, são paulo, brasil \\ orcid id: https://orcid.org/0000-0003-3170-293x
}

resumo

Neste artigo, procuramos discutir a recorrência do racismo e do preconceito sobre as vidas e as infâncias negras, diante da agenda regressiva que tem bloqueado o campo das políticas de inclusão social e educacional. Seguindo as investigações inauguradas por Foucault acerca da hipótese do biopoder, revisitamos alguns de seus intérpretes, com o objetivo de discutir os desafios lançados pelo racismo para o governo pedagógico das infâncias e para uma educação dos rostos negros, como campo político de lutas em que e a necropolítica se faz presente e evidencia a dimensão tanatológica da biopolítica. Para tanto, retraçamos algumas cenas da história dos dispositivos de inclusão - em especial, aquelas políticas voltadas às populações negras -, refletimos sobre o racismo incrustado em nosso inconsciente histórico e discutimos a forma como repercute na educação dos rostos em nosso país. Problematizamos, dessa forma, as peculiaridades do preconceito racial brasileiro e exploramos sua face necropolítica, quando voltada ao governo sobre as infâncias e a educação dos rostos negros. Concluímos que essa forma de governamentalidade e de educação necessitam de um movimento de desrostificação para que encontremos no devir que repercute sobre as infâncias e os rostos negros uma clandestinidade capaz de se insurgir contra as ordens majoritárias do homem-brancoheterossexual-cristão-europeu e de criar processos de subjetivação em que possa se aliar a multiplicidade de outros devires minoritários.

palavras-chave: infâncias negras; governamentalidade; necropolítica; devires minoritários; educação do rosto.

\section{governmentality, necropolitics, black childhood and education of the face}

abstract

In this article, we seek to discuss the recurrence of racism and prejudice toward black lives and childhoods, in spite of repeated initiatives to overcome it by social and educational policy-makers. Following the investigations launched by Michel Foucault on the biopower hypothesis, we revisit some of his interpreters, with the objective of discussing the challenges posed by racism to pedagogical provisions for black children and-following on a concept offered by Emmanuel Levinas--an education of the Face (el Rostro), as a weapon in the political field of struggle against the thanatological dimension of biopolitics. To do so, we retrace some scenes from the history of inclusion devices - especially those policies aimed at black populations. We reflect on the racism embedded in our historical

\footnotetext{
${ }^{1}$ E-mail: divino.js21@uol.com.br

2 E-mail: jrdavisao@gmail.com

${ }^{3}$ E-mail: pedro.pagni@unesp.br
} 
necropolítica, governo sobre as infâncias negras e educação do rosto

unconscious and discuss how it affects the education of the black Face in our country. We problematize the peculiarities of Brazilian racial prejudice and explore its necropolitical positioning when it comes to the governance of black childhoods. We conclude that the current form of governmentality and education needs a movement of de-rostificationdeconstuction of the black Face--in order to identify a future for black children that makes it possible to rise up against the hegemonic order of the white-male-heterosexual-christianEuropean, and to create processes of subjectivation that can build solidarity with the multiplicity of others-becoming-minoritarian.

keywords: black childhoods; governmentality; necropolitics; becoming-minority; education of the face.

\section{necropolítica, gobierno sobre las infancias y educación del rostro}

\section{resumen}

En este artículo discutimos la recurrencia del racismo y los prejuicios sobre la vida y las infancias negras, ante los retrocesos que han bloqueado el campo de las políticas de inclusión social y educativas. Siguiendo las investigaciones iniciadas por Foucault sobre la hipótesis del biopoder, revisamos algunos de sus intérpretes, con el objetivo de discutir los desafíos que plantea el racismo para el gobierno pedagógico de las infancias y para la educación de los rostros negros, como campo político de luchas donde la necropolítica está presente y resalta la dimensión tanatológica de la biopolítica. Para ello, repasamos algunas escenas de la historia de los dispositivos de inclusión - especialmente aquellas políticas dirigidas a poblaciones negras -, reflexionamos sobre el racismo incrustado en nuestro inconsciente histórico y discutimos cómo él afecta la educación de rostros en el país. De esta manera, problematizamos las peculiaridades del prejuicio racial brasileño y exploramos su rostro necropolítico, cuando se trata del gobierno sobre la niñez y la educación de los rostros negros. Concluimos que esta forma de gobernamentalidad y educación necesita de un movimiento de desrostificación para que podamos encontrar en el devenir que afecta a las/os niñas/os y rostros negros una clandestinidad capaz de levantarse contra las órdenes mayoritarias del hombre blanco-heterosexual-cristiano-europeo y crear procesos de subjetivación en los que se puede combinar la multiplicidad de otros devenires menores.

palabras-clave: infancias negras; gubernamentalidad; necropolítica; devenires menores; educación del rosto. 


\title{
necropolítica, governo sobre as infâncias negras e educação do rosto
}

\author{
A questão do século XX é a linha da cor.
}

W. E. B. Du Bois

\section{introdução}

Atualmente, encontra-se em marcha uma verdadeira agenda regressiva que mina as conquistas alcançadas pelas políticas inclusivas no país, com vistas a restabelecer a ordem ditada pelo homem branco, heterossexual, de preferência de classe média-alta e cristão, a qual reativa os devires majoritários, quando se sentem ameaçados pelo que acusam de ser o caos produzido pelos devires minoritários que ganharam corpo na esfera pública, nas últimas décadas (Brown, 2019; Chamayou, 2020). Essa agenda conservadora naturaliza as desigualdades resultantes das diferenças étnico-raciais, reforça a propagação do gênero binário e da condição cisgênera; nega o direito à terra aos povos originários indígenas, quilombolas e ribeirinhos e destrói o meio ambiente.Ademais, apoia discursos de retirada de direitos das pessoas com deficiência, para se firmar por meio do Estado e, mesmo o contrariando, com a complacência e estímulo do neoliberalismo econômico. Essas medidas de força e contenção adotadas pelo Estado neoliberal se efetivam no âmbito da própria democracia, incrustando nela elementos fascistas que a esvaziam sem eliminá-la formalmente. Todo esse rearranjo tem se dado em função de se garantir o acúmulo de lucros e dividendos, sob a movimentação do capital financeiro (Dardot; Laval, 2016; Lazzarato, 2019).

Conforme sugere Gil (2018), esse rearranjo político e econômico se sustenta em práticas populistas que necessitam criar um perigo, como o da perda de identidade, e mobilizar um desejo para que o indivíduo se sinta incluído em uma massa relativamente homogênea. É por essa via que o populismo atua intensamente sobre a subjetividade do povo e amplia ainda mais a fratura biopolítica do corpo social (Agamben, 2005). A ordem ou a prioridade de qual devir minoritário repercute sobre a pele e é designado como perigo pouco importam; sendo alguns mais combatidos do que outros, dependendo da formação cultural na qual emergem e, principalmente, de sua eficácia para mobilizar uma memória inconsciente reativa e uma descarga sobre aquele corpo que o expressa em signos. 
necropolítica, governo sobre as infâncias negras e educação do rosto

Analogamente à reprogramação das racionalidades de governo do mercado, segundo frisa Grégoire Chamayou (2020), o gerencialismo passa a governar, concomitantemente, as políticas estatais e as nossas existências, ordenando o fluxo dos desejos para objetos de consumo. Os signos mobilizadores são mais ou menos aleatórios, porém, estão em conformidade com os cálculos do biopoder e de seus jogos, no neoliberalismo, que assume em cada país feições próprias.

A novidade neoliberal é que os efeitos de poder que esses signos exercem sobre os corpos intensificam formas autoritárias e violentas de existência. Violência, em geral, autorizada por uma mentalidade política de corte claramente fascista, para que se descarreguem contra os corpos que portam devires minoritários as tensões e medos que seus modos de existir provocam. Essas tensões passam a ser descarregadas numa espécie de economia que fomenta a circulação do ódio, identificando sempre os inimigos da cultura naqueles povos que encarnam os devires negros, as comunidades homossexuais, os indivíduos transgêneros e as pessoas com deficiência. Para funcionar essa política do olhar, bastam a cor da pele, os traços físicos, os trejeitos corporais, os aspectos fenotípicos, a roupa, a maneira de viver etc. Ou seja, bastaria estar em uma pele que recobre o corpo, a qual não se tem como esconder, para se identificar e ser identificado como um outro ameaçador, sobre o qual recai a vigilância policial, a repressão, a criminalização e o preconceito (Agamben, 2015).

O nosso objetivo, neste trabalho, é discutir como o rosto negro entra no campo de batalha, entre a biopolítica e a necropolítica, em uma sociedade cuja democracia convive hibridamente com o fascismo. É sob o escudo desse híbrido de democracia e de fascismo que diferentes populações e comunidades estão submetidas a uma política de morte que sempre fora, paradoxalmente, praticada ou estimulada pelo Estado moderno, que se anunciou, desde sua origem, como promotor da vida das populações, as quais se encarregou de governar e proteger. Se a prerrogativa do Estado moderno para governar estava assentada no princípio do "fazer viver e deixar morrer" (Foucault, 1988, p. 130), em contraponto ao antigo poder soberano, cuja força política se sustentava sobre o "fazer morrer e deixar viver" (Foucault, 1988, p. 130), na realidade, esses diferentes modos de se exercer o 
silva; almeida; pagni

governo da vida nunca se separaram definitivamente, e nisso consiste o paradoxo inerente à governamentalidade biopolítica.

Segundo assinala Esposito (2010), a biopolítica está sempre na iminência de se transformar em uma tanatopolítica ${ }^{4}$. É dessa perspectiva que nos propomos pensar o governo das infâncias negras e o modo como elas estão entregues a uma política de morte, a qual se instalou em nosso país desde sua fundação e se sustenta num "passado que não passou" e que, portanto, se atualiza todos os dias, nas variadas formas de discriminação racial e de preconceitos que produzem a morte simbólica e concreta de pessoas negras.

A questão que gostaríamos de discutir, particularmente, é a forma como se refrata, na sociedade brasileira, certa cultura é patriarcal e, mentalidade escravagista que parece estar incrustadas no inconsciente social e, reativar uma memória cruel que, se encarna em figuras de uma ultradireita e em uma parcela da população que se viu ameaçada em seus devires majoritários na atualidade. Devires majoritários expressos na imagem de homem, branco, heterossexual, aparentemente próspero, próximo a um corpo espécie mediano, mesmo que a sua inscrição não o reporte a essa representação ou registro de si - que ela seja uma

\footnotetext{
4 Neste artigo, sustentamos uma perspectiva mais próxima a proposição de Foucault, mas reconhecemos que há distinções entre a noção de tanatopolítica e necropolítica. A hipótese do biopoder elaborada por Foucault na década de 1970 gerou complexas e variadas interpretações sobre a biopolítica, uma vez que o nexo foucaultiano carrega consigo o caráter experimental e uma abertura capaz de produzir novos questionamentos. Nesse campo destaca-se inicialmente a leitura de Agamben, filósofo italiano que se apropriou do conceito para desenvolver seu projeto homo sacer. No alvorecer dos anos 2000, outro italiano, dessa vez, Roberto Esposito, relendo as análises de Foucault sobre as doenças do poder em um contexto marcado pelo terrorismo propôs outra interpretação aquilo que entendeu ser uma indecisão de Foucault. Para resolver essa questão Esposito (2010) lançou uma provocação acerca do enigmático funcionamento da biopolítica mediante uma reativação soberana da dimensão tanatopolítica exemplificada no caso do nazismo. Para Esposito (2010) essa dialética possui uma conotação imunitária que é inerente as sociedades modernas de modo que "[...] ligar o sujeito moderno ao horizonte da segurança imunitária significa reconhecer a aporia em que a sua experiência fica presa: a de procurar refúgio da vida nas mesmas potências que impedem o seu desenvolvimento." (ESPOSITO, 2010, p. 88). Entendida como proteção negativa da vida a biopolítica transforma-se frequentemente em obra da morte. Recentemente, reportando a essa constituição negativa da comunidade, Achille Mbembe (2018) explorou essa mesma brecha, porém, para tratar da constituição necropolítica das colônias mediante o dispositivo da plantation que em última instância baseia-se no paradigma do campo de concentração. De fato, as referências de Foucault à organização do poder nas colônias são escassas, nesse sentido, Mbembe (2018) revela-se de grande atualidade. Outro estudioso da questão racial Paul Gilroy (2007, p. 8990) chama atenção para aspectos similares no pensamento do filósofo francês, especialmente, para o fato de Foucault não ligar explicitamente sua arqueologia das ciências do homem à emergência de uma episteme racial.
} 
necropolítica, governo sobre as infâncias negras e educação do rosto

fantasia, um fantasma ou um delírio que o faz se sentir seguro por sua integração. Os corpos que não se enquadram nos registros acima, tais como o corpo da travesti, do transgênero e das mulheres, produzem contra si mesmos o furor, conforme os dados estatísticos oficiais em termos de violência e homicídios. Se a esses signos se aliar o rosto negro, se incorporar a etnia africana e se viver em comunidades de periferia, os índices são ainda mais alarmantes.

Para se evitar esse ponto de transbordo, as políticas afirmativas, inclusivas e de cotas raciais foram criadas nas últimas décadas. Nesse jogo de forças, sequer a destinação das políticas de inclusão para o público da educação especial, ou seja, para as pessoas com deficiência, foi poupada. Mesmo que tais políticas os tivessem privilegiado no passado recente, agora estão também sob ataque.

A questão que discutimos neste artigo é o porquê desse refluxo, no âmbito da emergência dos dispositivos de inclusão, e, principalmente, as possíveis razões de o governo das infâncias negras ter sido secundarizado pelas escolas e por uma pedagogia que, estrategicamente, governa o rosto, minando-o como campo de disputa política. Isso significa discutir que, no âmbito dessas políticas e pedagogias, a afrodescendência foi tratada como estigma marcadamente racista, na medida em que a educação assumiu certa indiferença em relação aos devires negros que repercutiam sobre o rosto educado e deixou à míngua a sua potencialidade para curto-circuitar a face necropolítica dessa biopolítica à brasileira.

\section{racismo, déficit ontológico do "ser negro" e "o passado que não passou"}

Como escrevera José Peixoto de Azevedo (2018, p. 16), o racismo e a escravidão de negras e negros, no Brasil, remetem a "um passado que não passou". A imagem desse passado que não passou se atualiza, permanentemente, em práticas racistas cotidianas perpetradas contra esse povo. Dizer de um passado que não passou, nesse caso, é dizer de um presente genocida que insiste em subjugar, humilhar, explorar e exterminar aqueles e aquelas que trazem, em seus corpos, os signos da afrodescendência. Essas práticas nos dão a medida do racismo que há muito se instalou nas entranhas desta terra brasilis, o qual tem posto em movimento, por séculos, a mentalidade de uma elite econômica e política branca escravagista, 
que até hoje não consegue conter o ressentimento, ao se deparar com negros e negras circulando nos espaços e ocupando funções antes reservadas aos brancos.

A presença da pele negra nesses lugares soa como uma afronta aos privilégios brancos, ao mesmo tempo em que anuncia a possibilidade de quebra de uma silenciosa estratificação social, sempre justificada pelos discursos da meritocracia, da democracia racial e da igualdade de direitos entre brancos e negros. É essa herança racista que perdura até nossos dias e se alimenta do extermínio, não só simbólico, mas concreto da população negra, como aquela que sempre esteve condenada a ser morta pela polícia ou a morrer prematuramente, por falta de acesso à saúde, à educação, ao emprego e à moradia decentes.

A sombra da morte constituiu desde sempre uma ameaça à vida de negros e negras, não só aqui nas periferias das cidades brasileiras, como também em qualquer parte do mundo em que a cor da pele significa ser "menos" - "um déficit ontológico." (Pelbart, 2019, p. 172). É dessa perspectiva que gostaríamos de pensar a morte simbólica e a morte concreta das infâncias negras, no Brasil, no momento em que o extermínio dos povos negros, sobretudo da juventude que habita os grandes centros urbanos, vem embalado por discursos políticos que legitimam e autorizam a morte desse povo, "[...] sob a alegação de que bandido bom é bandido morto, supondo-se uma equivalência entre negro/pobre/bandido [...]"(Pelbart, 2018, p. 19).

Ser negro, no Brasil, significa ter três vezes mais chances de morrer assassinado pela polícia do que uma pessoa de pele branca. Esse risco triplica, quando se trata de crianças e adolescentes negros. ${ }^{5}$ Se a morte concreta constitui um risco iminente, há ainda um outro tipo de morte, menos visível do que a morte física, a qual recai sobre o corpo e a vida de crianças negras. Trata-se da violência cotidiana, manifestada pelo preconceito racial que produz feridas psíquicas profundas, ao submeter meninos e meninas a situações de humilhação, de

\footnotetext{
5 Dados de 2019, divulgados pelo Fórum Brasileiro de Segurança Pública e publicados no g1.globo.com/sp, em outubro de 2020, revelam que, das 4971 mortes de crianças e adolescentes (idade de 0-19 anos), de forma violenta, em 21 Estados brasileiros, 75\% eram negras. Disponível em: <g1.globo.com/sp/são-paulo/noticia/2020/10/18/brasil> Acesso em: 15 out. 2020.
} 
necropolítica, governo sobre as infâncias negras e educação do rosto

subjugação, de agressões físicas e psicológicas que destroem a autoestima, a dignidade e a vida das crianças.

Desde muito cedo, aprendemos que há um déficit ontológico, um ser "menos", associado à cor da pele negra, e a pele branca é exaltada como sinônimo de beleza, de dignidade e de superioridade. Esse ser "menos" ou esse ser "mais", caracterizados pela cor da pele, constituem um signo que demarca muito precocemente as vidas que devem ser dignificadas e aquelas que podem ser humilhadas e descartadas, sem que se produza comoção (Butler, 2017). Definem, já de partida, o modo como crianças negras serão tratadas nos espaços de socialização, como, por exemplo, na escola, na relação com outras crianças e com os adultos responsáveis pelo cuidado delas, nesses espaços. O ingresso no mundo da violência racista, tanto para a criança negra quanto para a criança branca, aquela como vítima e esta como algoz, ainda que ambas sejam vítimas, ocorre muito cedo.

Assim, iniciamos prematuramente o nosso curso de racismo, em que somos submetidos às suas extravagâncias, sem que saibamos, ao certo, do que se trata. Se sou branco ou branca, aprendo, nesse jogo, que um negro não é um igual e será sempre um negro. Se sou negro ou negra, descubro aturdido que não sou um igual, porque tenho a pele negra. No caso da criança negra, trata-se de uma descoberta dolorosa, perturbadora, pois com ela se tem a consciência de que já não se está mais em casa e de que a paz não retornará jamais, pois, de agora em diante, ela terá que viver encerrada numa espécie de “[...] autenticidade sem descanso [...]. A pele não é algo que se possa arrancar" (Frenette, 2000, p. 29). A criança negra se perceberá submetida, cotidianamente, ao escrutínio do olhar branco, o qual funciona como uma régua que estabelece a medida de todas as coisas.

As narrativas de crianças negras sobre o preconceito por elas sofrido, em diferentes espaços, ou as memórias de negras e negros adultos acerca de discriminações sofridas na infância há muito evidenciam a perversidade de uma sociedade estruturada numa cultura racista. Os signos que caracterizam o corpo afrodescendente funcionam como marcas, principalmente a cor da pele e a textura dos cabelos, as quais definem, previamente, quais lugares eles/elas devem ocupar socialmente, bem como definem a distância que se estabelece entre pele negra e pele 
branca. Assim se dá o racismo de marca, como um dispositivo sempre disponível a ser acionado, a depender do contexto, das experiências sobre as quais se sedimentam as relações entre negros e brancos. O racismo de marca define-se pelos traços fenotípicos e pela aparência racial, o que poderá determinar as variações na intensidade das práticas discriminatórias (Nogueira, 2006; Lopes, 2013a).

É nesse momento que a sagacidade adulta branca, que busca ocultar e negar seus gestos racistas, aparece de maneira escandalosa no flagrante preconceito denunciado pelos movimentos negros, pelas instituições defensoras dos direitos humanos e os enquadramentos dos meios de comunicação. Parece-nos que esse flagrante preconceito que penetra pelos poros se manifesta em sua forma genuína nas relações infantis. Vejamos um relato revelador do que a arrogância racista dissimula em seus gestos, mas que emerge incontrolada na relação entre crianças negras e brancas: um garoto negro, o qual deve ter por volta de oito anos e é estudante de uma escola particular, conta ao pai o que sua coleguinha branca lhe disse: "Tem uma amiga no transporte da escola, ela me contou que quase encostei nela, e ela disse 'eu tenho nojo de encostar em negro'" ${ }^{6}$

Apresentamos, a seguir, dois relatos de preconceitos sofridos por mulheres negras, colhidos e analisados pela pesquisadora Jussara de Cássia Soares Lopes (2013b) em sua Dissertação de Mestrado, publicados em artigo. São testemunhos de mulheres negras adultas que narram suas memórias de infância negra no contexto escolar. Primeiro relato:

Minha adolescência e minha infância foram bem difíceis devido ao preconceito dos colegas, isto faz a gente pensar que nasceu com algum defeito; que o problema é com agente que nasceu negra, e não com as pessoas que nos discriminam. Portanto, na minha infância, imaginava que se tivesse nascido branca, de cabelos lisos, seria bem aceita pelos colegas. [...] Queria muito ter nascido mais clara, mas o que mais me incomodava era o cabelo "duro". Acho que para ser mais aceita e para parecer com as pessoas "brancas", desde pequena a minha mãe começou a passar creme alisante no meu cabelo e no das minhas irmãs. Penso que para não destoar muito das pessoas de cabelo "bom". Lembro-me que meus coleguinhas sempre me chamavam de "Tia Anastácia", aquela do Sitio do pica-pau amarelo. Eles gozavam muito dos meus cabelos, e olha que eles viviam presos, minha mãe fazia grandes coques ou

6 Disponível no Portal Geledés <geledes.org.br/filho-de-andre-marinho-ex-broz-e-vitima-deracismo>. Acesso em: 11 nov. 2020. 
necropolítica, governo sobre as infâncias negras e educação do rosto

tranças nos meus cabelos. Eu era bem pequena, cursava a $2^{\mathrm{a}}$ ou $3^{\mathrm{a}}$ série do ensino fundamental, e sei que ficava muito chateada com os colegas, mas como era muito tímida, não brigava e nem retrucava, apenas me calava. Alguns colegas não queriam brincar comigo, principalmente se a brincadeira tivesse que pegar na mão. Engraçado, me lembro de que algumas professoras ficavam espantadas por eu andar sempre arrumadinha e limpinha, e as tarefas serem sempre bem feitas. Porque na concepção delas, os negros andavam sujos, não tinham higiene e, com certeza, eram muito pobres. Quanto à discriminação de gênero, esta era mais clara para todas as meninas, de cor ou não, sempre havia brincadeiras que os colegas, as professoras ou até mesmo os nossos pais não nos deixavam participar por acharem que eram brincadeiras de meninos [...] (Vencedora, 01/2013). (Lopes, 2013b, p. 174).

Segundo relato:

Meu primeiro contato com a escola foi inesquecível. Aos seis anos, fui ao primeiro dia de aula sozinha, porque minha mãe estava trabalhando e meu pai estava "por aí". Chegando à escola, uma professora me encaminhou para uma sala de alunos com necessidades especiais, das mais diversas. $\mathrm{Na}$ salinha ao lado, estava uma turma considerada sem dificuldades em todos os aspectos, pois todas as crianças ali vinham de famílias com poder aquisitivo e muito influentes na cidade. Logo questionei a professora do porquê de estar naquela sala, pois eu não possuía nenhuma deficiência. (Guerreira, 01/2013). (Lopes, 2013b, p. 175).

Os quadros e relatos de memórias acima não só evidenciam o subterrâneo de um passado que não passou, mas dão também mostras da cruel medida com que o olhar branco mede, desde a infância, a vida de uma negra e de um negro. Conforme nos revela Frenette (2000), essas atitudes rotineiras, e muitas vezes tratadas como corriqueiras, no cotidiano das infâncias negras, no Brasil, expõem os aspectos desagregadores do racismo que destrói subjetivamente aqueles que são a eles expostos, na maioria das vezes, de maneira indefesa. Essa é a aniquilação subjetiva que se repete dia após dia e que mina o amor-próprio de suas vítimas, e ela está baseada no terrorismo estético, por meio do qual se humilha todo um povo, dizendo-lhe diuturnamente que a beleza é branca.

Com efeito, as vítimas primeiras dessa realidade são as crianças negras, as quais muito cedo terão que deixar a proteção da família para enfrentar a escola, espaço em que maioria das crianças e professores são brancos e poucos estão preparados para lidar com as questões raciais. Esse é o "mundo cão" da "besta-fera" do racismo que a criança negra terá que enfrentar, com suas escassas armas e, se tiver sorte, com algum amparo da escola ou de alguns professores e professoras. 
Mas será nesse jogo das inumeráveis humilhações, agressões e de injúrias explícitas ou veladas, lançadas contra a cor da sua pele, que a criança vai se dar conta de que é diferente, ao mesmo tempo que se vê obrigada a desenvolver modos de resistência os quais lhe possibilitem manter a sanidade.

A morte não se dá somente no plano simbólico das representações. O negro, no Brasil, morre de muitos modos. Morre pelo cancelamento de sua história e pelos efeitos dos interditos solidificados que impossibilitam, quando não limitam, que brancos tenham a experiência da alteridade negra. O passado que não passou se atualiza também na morte concreta das infâncias negras brasileiras, noticiadas pelos jornais e denunciadas pelos movimentos negros e famílias das vítimas. O extermínio concreto desses corpos infantis é a realização do que Achille Mbembe (2018) denominou necropolítica, identificada com as formas contemporâneas de atuação do Estado e que submete a vida ao poder da morte, assentado numa política racializadora e legitimadora do antigo poder soberano de dispor sobre a vida e a morte. Mbembe (2018, p. 18) afirma que, “[...] na economia do biopoder, a função do racismo é regular a distribuição da morte e tornar possíveis as funções assassinas do Estado". É por essa via que são produzidas a legitimação e a aceitação da morte da população negra7, sem comoção ou luto.

Essas informações e aqueles relatos nos mostram a vulnerabilidade dos corpos negros e, sobretudo, a ausência de proteção dispensada pela governamentalidade estatal, em instituições como a escola, fazendo atuar aí o rosto como uma máquina de invisibilidade e de conflito político. Ao invés de iluminar a face potencialmente ingovernável e criativa desse rosto, este é, por sua vez, apresentado como sombrio, por vezes monstruoso, segundo seus enquadramentos majoritários. E cada um desses segmentos da população, assinalados pela encarnação de suas diferenças e pelo quanto elas se relacionam aos seus respectivos déficits ontológicos, lhe conferem um lugar na esfera pública e na participação política, hierarquizando-as conforme uma racionalidade econômica e um cálculo de

\footnotetext{
${ }^{7}$ Em 2019, até o mês de outubro, na cidade do Rio de Janeiro, 47 adolescentes e crianças foram feridos por balas perdidas disparadas por policiais, traficantes e milicianos. Nesse mesmo período do ano, 24 crianças foram mortas, vitimadas pelas mesmas ações (Deister, 2019).
} 
necropolítica, governo sobre as infâncias negras e educação do rosto

biopoder, o qual, antes de propiciar a sua afirmação como ser, continua a minorizálos à condição de infra-humanidade (Gilroy, 2007).

O problema é que, mesmo subjugado a essa racionalidade econômica na qual reside certa promessa de inclusão, no cálculo do biopoder, nesse povo que, desde sua infância, é assim governado pedagógica e politicamente, ainda perdura a desconfiança de uma ameaça imemorial, caracterizada pela cor da pele e por um rosto que parece sempre sugerir um outro, distinto de um nós; em geral, inferior, por mais que tenha cumprido rigorosamente o programa de sua prosperidade econômica. É esse problema, dentre outros, que não conseguimos vencer, mesmo com políticas de inclusão voltadas a essa população no ensino superior; até porque, como analisado até o momento, as infâncias negras sobreviveram a esse governo pedagógico e escolar - por vezes, omisso, mas também irresponsável, por não oferecer a elas e suas famílias sequer os dispositivos que lhe assegurariam a própria existência - paradoxalmente, colocam a essa população uma exigência extrema, no ensino superior.

Embora essas políticas garantam o direito de acesso à população negra, nem sempre elas garantem a sua permanência, sendo necessário se articularem com outras. Mais uma vez, é imperioso despender um esforço para além daquele exigido dos demais segmentos, sem contar toda a cultura elitista emeritocrática das universidades brasileiras, a qual enfrentam, junto a outros estudantes que encarnam diferenças outras, ao fazerem circular devires minoritários que até pouco tempo não eram vistos nos rostos dos universitários ou, quando percebidos, eram ignorados, como mais uma paisagem que perambulava pelos seus corredores. Afinal, que formação cultural foi essa, presente em nossas escolas e universidades, que invisibiliza esse rosto, a ponto de ignorá-lo e tratá-lo como indiferente, mesmo ante uma conjuntura política na qual teve reconhecidos os seus direitos de acesso a essas instituições e suas imagens propagadas como sendo para todos?

\section{Por uma pedagogia do rosto negro e de outro governo para suas infâncias}

Ao mobilizar o rosto levinasiano, Butler (2019) procura evidenciar o outro, sobretudo esse outro enquanto produto de certas relações de poder que visam a 
diminuir a humanidade daqueles que são alvos da interpelação do Ocidente enfurecido. O rosto revela-nos a precariedade do outro, escreve a autora:

Quando consideramos as formas convencionais em que pensamos sobre a humanização e a desumanização, debatemo-nos com a suposição de que aqueles que são representados, especialmente os que têm uma autorrepresentação, têm também uma chance maior de serem humanizados, e aqueles que não têm essa chance de se representar correm o risco maior de serem tratados como menos do que humanos, de serem vistos como menos do que humanos, ou, na verdade de não serem vistos de forma alguma. (Butler, 2019, p. 123124).

O rosto é a condição de abertura ao outro, portanto, porta algo de inapreensível e irrepresentável, mas também é constantemente mobilizado pelos enquadramentos sociais, para tornar visível e produzir o inimigo público, ou a vida que não é digna de enlutamento. A chave para compreender essa produção social dos rostos encontra-se nas dinâmicas das relações de poder existentes entre diferentes grupos, povos, populações e nações. Aqueles que não detêm os veículos de produção das mídias ou algum grau de auto-organização política capaz de gerar uma autorrepresentação estão sujeitos a enquadramentos violentos, estereotipados e desumanizados.

Para a filósofa, é o rosto árabe associado de personagens históricos, como Osama Bin Laden, Yasser Arafat e Saddam Hussein, em jogo na cena de desumanização. Por sua vez, essa sua análise focalizada no rosto, na voz e na poesia dos detentos de Guantánamo ganha um contorno mais preciso, quando argumenta que

[e]sses enquadramentos são atuantes em situações de prisão e tortura, mas também nas políticas de imigração [...] Formas de racismo instituídas e ativas no nível da percepção tendem a produzir versões icônicas de populações que são eminentemente lamentáveis e de outras cuja perda não é perda, é que não é passível de luto. A distribuição diferencial tem implicações sobre e por que e quando sentimentos disposições afetivas politicamente significativas, tais como horror, culpa, sadismo justificado, perda e indiferença. (Butler, 2017, p. 43-44).

Sob o ponto de vista genealógico, Butler (2017) aproxima-se de Foucault, no que diz respeito a essa noção de enquadramento enquanto uma objetivação dos sujeitos, graças a certos efeitos de verdade produzidos por enunciados, medidas de 
necropolítica, governo sobre as infâncias negras e educação do rosto

vigilância e técnicas de gestão das populações que criam a visibilidade do criminoso e do indivíduo perigoso.

Na concepção de Foucault, a produção do indivíduo ou do perigoso como risco biológico ou biopolítico encontra-se no cerne do racismo que está “[...] ligado ao funcionamento de um Estado que é obrigado a utilizar a raça, a eliminação das raças e a purificação da raça para exercer seu poder soberano." (Foucault, 1999, p. 309). Para Agamben (2015), o que está em jogo é a redução do homem à vida nua, fato consumado graças à proliferação desses mecanismos de identificação dos indivíduos por meio dos seus traços, feições e corporalidade, os quais que adquiriram grande impulso com o desenvolvimento da fotografia, haja vista que esta facilitou a captura e a reprodução dos rostos de sujeitos pretensamente criminosos. Com isso, pode-se dizer que o rosto enquanto invólucro exterior acompanha as técnicas de individualização do poder. Segundo Agamben (2015), esses dispositivos geram um reconhecimento cuja base repousa sobre o corpo biológico. No entanto, enquanto Agamben (2015) denuncia o campo como o paradigma político de produção da vida nua, Butler (2017) argumenta que o aumento da vulnerabilidade das populações não se deve a uma exclusão, mas à ação deliberada de certos estados, com vistas a distribuir a precariedade de modo diferencial.

Ao articular a questão da governamentalidade em Foucault, denunciando as prisões indefinidas que decorriam da desumanização dos prisioneiros e se aproximar da noção de necropolítica de Mbembe, para tratar os seus enquadramentos, Butler $(2017,2019)$ analisa os quadros da vida precária, enfatizando o papel ativo do Estado, o qual, favorecido pelos diversos modos de inteligibilidade fundamentais, concorre para a desumanização, mediante a minorização do rosto alheio. Afinal, assinala ela,

[...] o outro confere reconhecimento [...] em virtude de capacidades internas especiais para discernir quem eu posso ser, para ler meu rosto. Se meu rosto é de fato legível, só chega a sê-lo porque entra em um quadro de referência que condiciona sua legibilidade. Se alguém é capaz de me 'ler' enquanto outros não conseguem, será apenas porque aqueles têm talentos internos que faltam nestes? [...] se tivermos de responder eticamente a um rosto humano, primeiro tem de haver um quadro de referências para o humano que possa incluir qualquer número de variações como instâncias disponíveis. 
Mas, tendo em vista o quanto a representação visual do humano é discutida, talvez pareça que nossa capacidade de responder a um rosto como rosto humano seja condicionada e mediada por quadros de referência variavelmente humanizadores e desumanizadores. (Butler, 2015, p. 43).

Com isso, podemos reconduzir as suas interrogações sobre o rosto enquanto condição de reconhecibilidade ou apreensão do outro, a fim de pensar as relações entre as vidas, as infâncias negras e a escola, o que nos leva a considerar o desenvolvimento do preconceito e racismo brasileiro como resultado dos diversos enquadramentos raciais que identificam o rosto negro com signos da anormalidade, deficiência, animalidade e periculosidade. Afinal, quais são os enquadramentos atuantes no racismo brasileiro? Responder a essa questão em toda sua amplitude talvez não seja possível, contudo, sua importância e urgência nos impedem de nos esquivar à tarefa de denunciar e problematizar a produção de vidas precárias, cujos rostos reconhecemos como aqueles que estão relegados a um déficit ontológico, reconhecidos por uma ontologia do desvio, mas não por um modo de ser que vê, neste último, antes que uma ameaça, uma potência ingovernável.

A percepção de tal potência funcionaria como um start para o confronto com a dispersão normativa movida por formas de governamentalização neoliberal - por vezes, até incitadas por lutas identitárias -, e no encontro com as diferenças, produzindo subjetivações outras, à luz dos devires que atravessam o povo que falta(Deleuze, 1997). Se esses devires sugerem uma relação de rostidade com esse outro, em busca de tentar se haver com esses devires, de forma a produzir uma performance que exprime mais um deles - qual seja, o mais animalizado, o mais negro, o mais mulher, o mais minorizado, enfim, ou o menos colonizado do inconsciente -, o encontro com eles produz, senão uma correção do déficit ontológico, ao menos uma afirmação (expressiva) de uma existência ímpar, pulsante, ontologicamente marcada pela singularidade e pela diferença.

Contra essa dispersão, podemos destacar ao menos três pontos que atuam historicamente na manutenção do preconceito racial: a mídia, a política e o governo escolar da infância. Nesses pontos agem, respectivamente, os dispositivos do olhar, os mecanismos de governar e as tecnologias do expressar. É preciso atentar que esses pontos de cruzamento não são a origem do racismo, todavia tornaram foco de 
necropolítica, governo sobre as infâncias negras e educação do rosto

disputa de discursividades e visibilidades capazes de engendrar, acolher e fazer circular diversas práticas sociais e afetos no campo político. A começar pela mídia, desde as mais tradicionais, como os jornais, até as recentes redes sociais, as quais têm produzido, ao longo de sua história, o olhar altivo sobre os indivíduos negros, na maioria das vezes, modelando uma opinião pública ressentida e nutrida de preconceitos em função de um "multiculturalismo empresarial" (Gilroy, 2007). Certamente, aclamando o corpo negro e exaltando sua sensualidade carnavalesca ou sua destreza nos campos de futebol; não apaga os rostos estampados nos telejornais, tampouco, os índices reais de violência a que é submetido o povo negro.

No Brasil, o racismo de marca alija os rostos negros, porém, isso é paradoxal, porque existem elementos na cultura global de glamorização do corpo e da violência, como escreve um crítico:

[...] a proeminência atual conferida a corpos excepcionalmente bonitos e glamorosos, porém, racializados, não faz nada para mudar as formas cotidianas de hierarquia racial. As associações históricas de negritude com a infra-humanidade, brutalidade, crime, preguiça, fertilidade excessiva e ameaçadora, e assim por diante, continuam imperturbáveis. (Gilroy, 2007, p.42).

A precariedade tem rosto de mulher, negra e pobre, assim como captura esses devires que circulam e repercutem no rosto, em torno do qual se unificam, se subordinam a uma significância e subjetivação, que os exclui para fazer preponderar o do humano branco, masculino, hétero, de classe média-alta. Apesar da pressão social dos movimentos sociais e dos esforços de alguns governos, no Brasil, essa exclusão produzida por uma máquina abstrata de significância e subjetivação, como visto anteriormente, não cessou de organizar a exclusão social dos povos negros e pobres, lançando-os às garras das forças de repressão policial e ao aparelho judiciário. Afinal, o devir-negro do mundo (Mbembe, 2014) é acompanhado pelas investidas neoliberais que empobrecem os povos e brutalizam seus inimigos. Desde esse empobrecimento e brutalização, a infância negra é frequentemente capturada e barrada, na aurora do florescimento, submetida a uma educação do rosto e a formas de seu governo em instituições como a escola, reportando-nos ao terceiro ponto de dispersão. 
Antes disso, não é possível ignorar o terreno de disputa política e semiológica em torno do rosto, como destacam Deleuze e Guattari (2004, p. 50): “O rosto é uma política". Essa política consiste em definir os enquadramentos, a paisagem e o rosto a ser enfocado, produzido socialmente por uma "máquina abstrata de rostidade", isto é, por uma "[...] máquina que opera uma rostificação de todo o corpo, de suas imediações e de seus objetos, uma paisigificação de todos os mundos e meios"(Deleuze; Guattari, 2004, p. 49). Por sua vez, essa máquina de rostidade efetua "[...] agenciamentos de poder bastante particulares que impõem a significância e a subjetivação" (Deleuze; Guattari, 2004, p. 49), funcionando autoritária e despoticamente na unificação em torno de um rosto e gerando certo imperialismo semiológico, com o esmagamento de quaisquer outros e se protegendo das ameaças vindas de fora. Enfatizam os autores:

Trata-se de uma abolição organizada do corpo e das coordenadas corporais pelas quais passavam as semióticas polívocas ou multidimensionais. Os corpos serão disciplinados, a corporeidade será desfeita, promover-se-á a caça dos devires animais, levar-se-á a desterritorialização a um novo limitar, já que se saltará dos estratos orgânicos aos estratos de significância e de subjetivação. (Deleuze; Guattari, 2004, p. 49).

O rosto se perfaz, assim, como um porta-voz político que impõe uma determinação, caçando todos os demais devires não apreensíveis pela semiologia significante e se sobrepondo à corporeidade em torno da qual repercute. Diferentemente do racismo primitivo, no qual a figura do Outro se vislumbra na figura do estrangeiro, para esses filósofos, o racismo europeu procede por determinações de desvios das normalizações: “[...] em função do Homem Branco que pretende integrar em ondas cada vez mais excêntricas e retardadas os traços que não são conformes", seja para tolerá-las em determinadas condições e contextos, seja para apagá-las diante da incapacidade de "suportar a alteridade." (Deleuze; Guattari, 2004, p. 44). Ora, desse ponto de vista racista, [...] "não existe exterior, não existem pessoas de fora", mas "[s]ó existem pessoas que deveriam ser como nós", sendo esse o seu crime, formado por cadeias de significantes simultâneas e escolhas subjetivas que, antes de detectar as "partículas de um outro", se propagam por meio de “[...] ondas do mesmo até a extinção daquilo que não se 
necropolítica, governo sobre as infâncias negras e educação do rosto

deixa identificar (ou que só se deixa identificar a partir de tal ou qual desvio), e, ao mesmo tempo, a sua crueldade." (Deleuze; Guattari, 2004, p. 44-45).

Para Deleuze e Guattari (2004), esse racismo se justificaria em razão de a produção do rosto ocorrer por meio de uma "máquina abstrata", a qual, mesmo não fazendo do rosto um universal, funciona no sentido de compreendê-lo em uma ordem de razões e em uma cadeia de significantes, concernente, primeiro, à sua unidade ou o seu elemento e, segundo, ao seu julgamento ou escolha. Isso significa admitir que o rosto é definido em função de uma unidade ou de um elemento caracterizado por uma coisa ou outra, biunivocamente determinado - por exemplo, homem ou mulher, branco ou negro etc. -, a partir do qual é feita a escolha por um dos elementos, com a subsequente negação do outro. Mais do que um procedimento lógico, essa negação pela máquina abstrata rejeita "rostos não-conformes ou com ares suspeitos" para certos níveis de escolhas, enquanto, para todas as outras que escapam à relação biunívoca, opera no sentido de demarcar os seus desvios, ontologicamente falando. Dessa forma, ressaltam os autores, instauram-se “[...] relações binárias entre o que é aceito em uma primeira escolha e o que não é tolerado em uma segunda, em uma terceira, etc." (Deleuze; Guattari, 2004, p. 45).

O exemplo que mencionam, em relação à travesti, é emblemático: “[...] não é nem um homem nem uma mulher", pois "[...] a relação binária entre o 'não' de primeira categoria e um 'sim' de categoria seguinte que tanto pode marcar uma tolerância sob certas condições quanto indicar um inimigo que pode se abater a qualquer preço." (Deleuze; Guattari, 2004, p. 45). O que importa, porém, seria que a máquina abstrata nos inscreva e nos reconheça em certos enquadres, detectando nossos desvios, para que a máquina de rostidade opere de modo a generalizar e ordenar normalidades, similarmente aos dispositivos psiquiátricos de poder descritos por Foucault (2010); porém, utilizados como um maquinismo para explorar a sua face política, em um sentido mais amplo.

A sua dimensão educacional aparece, por sua vez, desde o cristianismo, quando o controle é exercido com respeito ao rosto e à paisagem, no sentido de compô-los e colocá-los em uma dada ordem hierárquica, a qual exclui o que não apreende em seus códigos prévios e a uma razão, produzindo uma 
desterritorialização absoluta. Até que ponto essa educação cristã conduziu a uma pedagogia do rosto, que engessa as figuras do professor e do aluno, restringindo-as a seus papéis e agenciamentos de poder, parece ser algo ainda a ser discutido. Contudo, podemos assegurar, pelo exposto anteriormente, que a pedagogia corroborou, no caso brasileiro, não somente essa educação do rosto apoiada nos operadores do maquinismo abstrato da rostidade, como também redundou em um racismo, sobretudo no que tange aos povos negros, cujos devires foram manipulados para produzir um dispositivo de inclusão, que, quando não governa, integrando-o à população, exclui e, por vezes, mata.

Nesse registro, o racismo em relação aos devires negros opera por meio, mais do que da identificação de uma ameaça por um processo de seleção e escolha aleatória, de uma condenação inscrita por essa máquina abstrata na pele negra e num rosto que encarna não propriamente uma individualidade, mas toda uma economia e organização do poder. Essa economia suprime tudo o que possa advir, tanto do corpo polívoco quanto dos devires minoritários do povo que falta, assim como os reúne em torno de um espírito único, universal, majoritário, o qual discrimina tudo o que dele escapa. Nisso consiste a rostificação que estigmatiza, preconcebe e discrimina, podendo até matar. Ela “[...] não opera por semelhança, mas por ordem de razões", consistindo numa operação “[...] muito mais inconsciente e maquínica que faz passar todo o corpo pela superfície esburacada", em que o rosto desempenha um papel de “[...] sobrecodificação para todas as [suas] partes descodificadas", e não de imagem ou de modelo (Deleuze; Guattari, 2004, p. 35). Nesse sistema de rostidade, repercutem os significantes e as suas cadeias, resultando num rosto que torna redundantes as redundâncias de significância e ressoa os embates daqueles devires da subjetividade, construindo uma lousa, para que o significante se inscreva, e escavando os buracos, a fim de que a subjetivação o atravesse, não apenas como consciência ou paixão, mas também como força e desejo, inconsciente e maquinicamente.

É nesse âmbito que se pode aludir a certa ultrapassagem da barreira da rostidade e pensar o rosto para além da forma estanque que organiza não somente o corpo, como também os agenciamentos de poder. E, pensamos nós, também em 
necropolítica, governo sobre as infâncias negras e educação do rosto

discutir a possibilidade, senão de uma educação sem rosto, ao menos de uma desrostificação que pode atravessar o muro de nosso racismo, reconhecê-lo em torno do modo como repercute sobre o nosso próprio rosto e desfigurá-lo, para que a força do olhar severo, que recrimina, estigmatiza, mata as infâncias negras, conjuntamente ao seu governo pedagógico, entrem em deriva.

Para tal intento, é melhor lidar com a sua face mais inumana, menos codificada, mais inconsciente, mais atinente à arte do que a filosofia, que implica encontrar na superfície desse rosto, de sua lousa ou de seu muro branco, uma deriva obscura e um devir clandestino, cujas forças conduzem a outras formas de subjetivação e a outra maquinaria abstrata.

\section{considerações finais}

Uma vez que o rosto é político, desfazer o rosto também o é, encontrando entre os devires com os quais se ocupa esse maquinismo um devir clandestino, o qual flexiona o arco, para que a flecha rompa com a rostidade instaurada e uma ordem de razão em que redundam os racismos de todas as espécies. Mas, para tanto, é preciso assumir, prudentemente, os traços da rostidade que pretendem escapar de seu maquinismo abstrato, desfazendo o rosto instaurado para "atravessar o muro do significante, romper com o buraco negro da subjetividade" (Deleuze; Guattari, 2004, p. 59), conhecendo-o melhor e mapeando suas linhas de fuga.

Não se trata de um retorno a um corpo polívoco, nem a devires animais que caracterizaram algumas formações sociais primitivas, tampouco de uma reterritorialização em que a cabeça volta assumir o seu protagonismo, num corpo organizado, muito menos retomar o corpo dos renegados como aqueles que encarnam devires minoritários e corporificam certa clandestinidade. Ao contrário disso, essa fuga pode ser encontrada no interior do próprio rosto, o qual apaga suas reminiscências e ignora os devires nômades, para se fixar, agenciando toda uma economia do poder, mas que pode encontrar no próprio inconsciente colonizado os sentidos de sua captura e de sua eventual deriva, de sua desrostificação:

É somente no interior do rosto, do fundo de seu buraco negro e em seu muro branco que os traços de rostidade poderão ser liberados, como os pássaros; não voltar a uma cabeça primitiva, mas inventar as combinações nas quais esses traços de paisageidade, eles mesmos 
liberados da paisagem, com traços de picturalidade, de musicalidade, eles mesmos liberados de seus respectivos códigos. (Deleuze; Guattari, 2004, p. 59-60)

Se a máquina abstrata da rostidade funciona, desterritorializando relativa ou absolutamente a multiplicidade dos devires em torno de uma unidade que a nega, ela também diagrama os seus traços ainda não codificados, como um valor positivo capaz de criar novas máquinas, sobretudo, quando opera uma verdadeira "desrostificação". Esse parece ser também, ao nosso juízo, o trabalho implícito ao governo pedagógico das infâncias negras que faria com que a educação do rosto na qual se apoia e a rostidade na qual seus planos se efetuam seja revista, reformulada, dando contornos a outras formas de governamentalidade, capazes não de tolerar, nem de aceitar, mas de acolher as infâncias negras.

Para Deleuze e Guattari, seria a "desrostificação” que “[...] libera de algum modo cabeças pesquisadoras que desfazem em sua passagem os estratos, que atravessam os muros da significância e iluminam buracos de subjetividade", abatendo as árvores enraizadas em prol de rizomas e conduzindo os fluxos em “[...] linhas de desterritorialização positiva ou de fuga criadora." (Deleuze; Guattari, 2004, p. 60). É nessa perspectiva aberta pelos filósofos da diferença que podemos conclamar a criação de formas outras de rostidade, de significação e subjetividade, reconhecendo a semiologia mista em que se movem, são capturadas e escapam.

Para essa rostidade, há uma forma de educação do rosto em que a diferença não pode ser apreendida pelos atuais dispositivos de inclusão; tampouco ser enquadrada, uma vez que se debruça sobre as suas forças mais inumanas, seus devires minoritários e uma deriva sem fim, em torno da qual se produziria um encontro com as diferenças, dentre as quais as agenciadas pelas infâncias negras. Afinal, se é para começarmos por algum momento da vida esse processo de educação do rosto, que seja pela infância, momento no qual o rosto começa organizar o corpo infante, dar-lhe e receber forma ainda num corpo sem órgãos. Aí também se encontraria a potência da vida em estado bruto, com os devires em circulação; sem uma prefiguração de majoração e de minoração prévia, facultando a produção de uma outra rostidade, desde que a cabeça pesquisadora dos educadores estivesse atenta aos seus traços e devires clandestinos, dentre os quais 
necropolítica, governo sobre as infâncias negras e educação do rosto

se destacam os devires negros. As infâncias negras, nesse processo, constituem um traço do rosto e da cor da pele que corporifica toda a história de luta de sua formação como um povo que falta, cujos devires não se dobram ao governo biopolítico da população, tampouco à sua arte pedagógica; um virtual que amplie a sua fratura e produz derivas, instigando os educadores a liberarem suas cabeças pesquisadoras.

Ao dirigir tais cabeças para outras searas, compondo a paisagem com o rosto em diacronia com a rostidade existente e vislumbrando, em seus traços clandestinos, toda uma cartografia se apresenta para ser desbravada; outras formas de subjetivação e de alteridade a serem construídas por essas cabeças pesquisadores, em busca de linhas de fuga com essas infâncias negras e de um trabalho meticuloso sobre seus ethos, para que outros devires minoritários também sejam percebidos, além das tecnologias de reconhecimento identitários.

Operar nesse terreno dos devires minoritários de um povo que falta parece ser a ambição dessa cartografia produzida pelas cabeças pesquisadoras: elaborar uma cartografia para tal e, à luz dela, produzir alianças possíveis, táticas e estratégicas, parecem-nos ser seu desafio político, no presente. Talvez, uma cartografia política, mais do que uma pedagogia, como o rosto que agora se afirma em uma diferença que extrapola toda codificação pela sua potência e pela sua possibilidade de transformar sua saída ou fuga em reversão, transformação, aliada a outros devires minoritários de um povo que falta e às diferenças produzidas pelos seus encontros.

\section{referências}

Agamben, G. Identidade sem pessoa. In: Agamben, G. Nudez. Belo Horizonte: Autêntica, 2015.

Azevedo, J. F. P. Eu, um crioulo. Série Pandemia. São Paulo: N-1 Edições, fev. 2018.

Brown. W. Nas ruínas do neoliberalismo: a ascensão da política antidemocrática no Ocidente. São Paulo: Editora Filosófica Politeia, 2019.

Butler, J. Relatar a si mesmo: crítica da violência ética. Belo Horizonte: Autêntica, 2015.

Butler, J. Quadros de guerra: quando a vida é passível de luto? 3. ed. Rio de Janeiro: Civilização Brasileira, 2017.

Butler, J. Vida precária: os poderes do luto e da violência. Belo Horizonte: Autêntica, 2019.

Chamayou, G. A sociedade ingovernável: uma genealogia do liberalismo autoritário. São Paulo: Ubu, 2020.

Dardot, P.; Laval, C.A Nova Razão do Mundo: ensaio sobre a Sociedade Neoliberal. São Paulo: Boitempo, 2016. 
Deister, J. Mês das crianças: 24 crianças e adolescentes mortos em ações policiais no Rio em 2019. Disponível em: https://www.brasildefatorj.com.br/2019/10/16/mes-dascriancas-24-criancas-e-adolescentes-mortos-em-acoes-policiais-no-rio-em-2019. Acesso em: 11 nov. 2020.

Deleuze, G. Crítica e Clínica. São Paulo: Editora 34, 1997.

Deleuze, G.; Guattari, F. Mil Platôs: capitalismo e esquizofrenia. São Paulo: Editora 34, 2004. Esposito, R. Bios: biopolítica e filosofia. Lisboa, Portugal: Edições 70, 2010.

Foucault, M. História da sexualidade: a vontade de saber. 1. ed. Rio de Janeiro: Graal, 1988.

Foucault, M. Em defesa da sociedade: curso do Collège de France (1975/1976). São Paulo: Martins Fontes, 1999.

Foucault, M. Os anormais: curso no Collège de France (1974-1975). 2. ed. São Paulo: Martins Fontes, 2010.

Frenette, M. Preto e branco: a importância da cor da pele. São Paulo: Publisher Brasil, 2000. Gil, J. Caos e ritmo. Lisboa: Relógio D’Água, 2018.

Gilroy, P. Entre campos: nações, cultura e fascínio da raça. São Paulo: Annablume, 2007.

Lazzarato, M. Fascismo ou revolução? O neoliberalismo em chave estratégica. São Paulo: N1 Edições, 2019.

Lopes, J. C. S. Os mecanismos de naturalização do racismo e do sexismo em meninas negras: memórias de assistentes sociais negras catrumanas. Dissertação (mestrado) Pontifícia Universidade Católica do Rio de Janeiro, Departamento de Serviço Social, 118f, 2013a.

Lopes, J. C. "À flor da pele": memórias do racismo e do sexismo na infância e na adolescência de assistentes sociais negras catrumanas. Libertas: Revista da Faculdade de Serviço Social de Juiz de Fora, v. 13, n. 1, p. 161 - 192, jan./jun. 2013b.

Mbembe, A. Crítica da razão negra. Lisboa, Portugal: Antígona, 2014.

Mbembe, A. Necropolítica. São Paulo: n-1 edições, 2018.

Nogueira, O. Preconceito racial de marca e preconceito racial de origem: sugestão de um quadro de referência para a interpretação do material sobre relações raciais no Brasil. São Paulo, Revista Tempo Social, 19(1), 287-308, 2006.

Peixoto, J. F. A. Eu, um crioulo. São Paulo: N-1 Edições, 2018.

Pelbart, P. P. O devir-negro do mundo. Revista CULT, n. 240, nov. 2018.

Pelbart, P. P. Ensaios do assombro. São Paulo: N-1 Edições, 2019.

recebido em: 20.11 .2020

aprovado em: 19.03.2021 